\title{
SYMPOSIUM B
}

\author{
Defect Properties And Processing \\ of High-Technology Nonmetallic Materials
}

The symposium "Defect Properties and Processing of High-Technology Nonmetallic Materials" is the first in the MRS series devoted exclusively to the rapidly expanding field of high-technology nonmetallic materials. The symposium provided a forum for dialogue between the ceramist and the physicist. By all accounts it was highly successful. The attendance was greater than had been anticipated and fluctuated between 100 and 150 for the 3 $1 / 2$ days, which included Thursday morning.

The properties of ceramics are very important when they are considered for practical devices. Warping, cracking, and shrinking limit the useful applications of ceramics.

Nonetheless, ceramic materials are currently used extensively and account for about $\$ 40$ billion in low valueadded products (glass, cement, etc.) and $\$ 2$ billion of high value-added components (electronics). At this meeting the sintering, plasma sintering, and shock compaction of useful ceramic materials were discussed. Densification rates are higher for shocked materials. Progress toward the production of reproducible ceramic parts is being made through materials preparation by hydrothermal and polymerization techniques and shock treatment.

One of the sessions dealt with structure and impurity distribution in a variety of binary and ternary oxides. $J$. Narayan summarized the recent advances, performed at Oak Ridge, relating to formation of metal precipitates by reduction treatment of oxides and how these often influence the physical and mechanical behavior of those materials. C.W. White, also of Oak Ridge, discussed recent work in the understanding of ion implantation of impurities into refractory oxides, especially $\alpha-\mathrm{Al}_{2} \mathrm{O}_{3}$, devoting attention to the use of Rutherford backscattering as a tool for assessing damage to both cation and anion sublattices and the location of the impurity after a variety of thermal treatments. These invited papers set the stage for a variety of contributions devoted to the influence of impurities upon phase stability and physical and mechanical behavior of a variety of oxides including electro-optical materials.

An important paper which reviewed the considerable recent progress in understanding reliability of brittle ceramics in mechanical service was presented by A.G. Evans of Berkeley. This, together with a survey of the influence of processing variables on the nature of defects in silicon carbide by R.F. Davis of North Carolina State, served to introduce a number of papers on advanced processing of ceramics, among which were several papers on shock modification.

The influence of point defects in $\alpha$-quartz has become an important technological as well as basic physics topic.

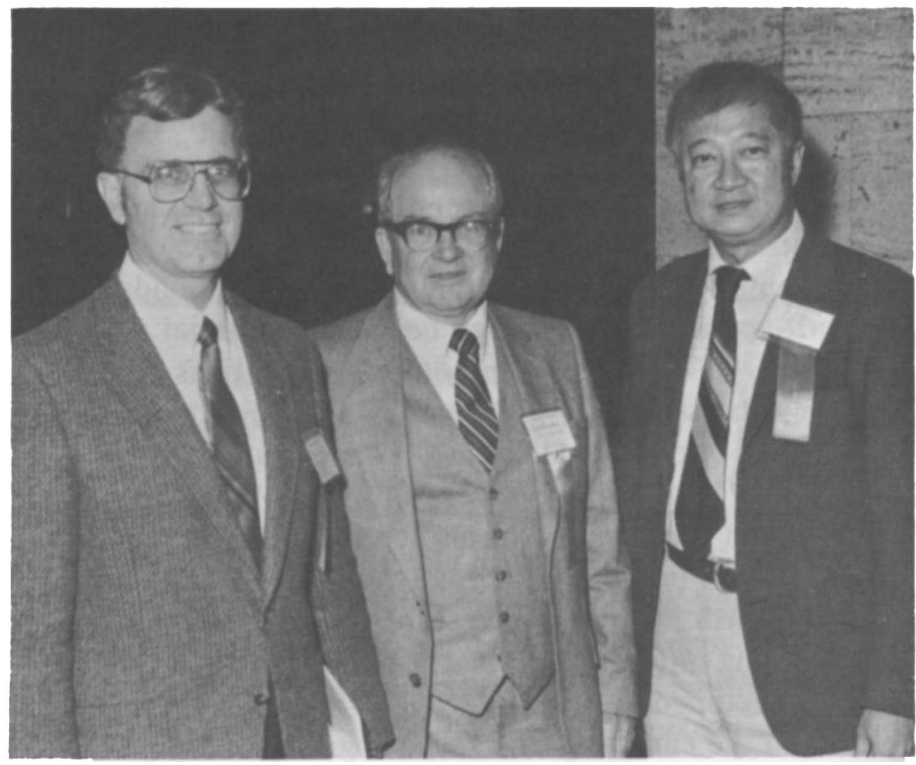

\section{W.A. SIBLEY (left), J.H. CRAWFORD and Y. CHEN}

Current progress in this area was summarized by D.R. Koehler of Sandia. Other papers on dielectric loss, photoplasticity, and photo-induced optical switching in insulators rounded out this session on potential device applications.

Three invited papers led off the session on transport phenomena. Unusual transport behaviors of compounds containing a dispersed second phase of small particles were elucidated by J.B. Wagner of Arizona State. A double header on diffusion mechanisms in oxides featured N.L. Peterson of Argonne and A.E. Hughes of Harwell. The former spoke on self-diffusion in $\mathrm{Cu}_{2} \mathrm{O}$ and $\mathrm{MnO}$ as a function of temperature and deviation from stoichiometry. Hughes discussed "short-circuit" diffusion paths in oxidation films, especially through grain boundaries.

One of the major highlights of Symposium B was the Wednesday afternoon session devoted to invited speakers surveying a wide range of problems applicable to research on insulating materials. These problems and needs ranged from the design of composite materials for electromechanical and electro-thermal applications, to the design of ceramic engines and the need for high power and low power solid state lasers and optical wave guide materials. V.J. Tennery of Oak Ridge and L.E. Cross of Penn State spoke to the need for new composite materials in the future. Tennery outlined the areas in which high temperature materials can be used and the defects which at present are responsible for inhibiting the possible application of these 
high temperature materials. It appears that diesel engines could profit significantly from the utilization of high temperature insulating materials. Cross discussed the need for piezoelectric ceramic and polymer composites for hydrophone sensing. Advanced research on these particular materials is of great importance. It is clear that materials such as $\mathrm{LiTaO}_{3}, \mathrm{LiNbO}_{3}$, and poled ceramics like $\mathrm{BaTiO}_{3}$ or $\mathrm{PbZrO}_{2}: \mathrm{PbTiO}_{2}$ are already extremely useful. If these materials can be made more structurally reliant, then new areas of application will appear. The requirements of small size and low thermal mass put rigorous limits upon the scale of the composite microstructures. Techniques to achieve the appropriate scaling in these materials are greatly needed.

Peter Moulton (Lincoln Lab), William Krupke (LLL), and Ma Saifi (Western Electric) discussed the utilization of insulating materials in the area of optical communications and processing. Rapid progress is being made on higher transmission materials for optical wave guides. Recent advances in fluoride materials are startling. It appears that optical communication over distances greater than fifty kilometers will be possible without amplification in some of these new materials. At the present time, the limitations on the fluoride type systems are trace impurities in the low part per million or high part per billion range of $\mathrm{Fe}^{2+}, \mathrm{Ni}^{2+}$, and $\mathrm{Cu}^{2+}$. There is a need for better detection of these impurities and methods to eliminate their presence from fluoride materials. Similarly, tunable solid state lasers which allow communication over a wide range of frequencies and make better use of satellite sensors are needed.

Moulton described systems which now are being put into operation. He presented ideas for several new efficient systems. In the area of high power lasers for inertial fusion, Krupke described the critical role of insulator materials in the development of high peak power solid state lasers. Materials have been developed which have exceptionally high resistance to damage in the presence of intense optical beams while having properties that optimize their functions. One difficult area is the removal of heat from the huge optical component materials that must be used. In some cases, crystalline systems will be utilized to enhance the thermal conductivity of the system so heat can be efficiently removed. This session was extremely exciting. The speakers presented relevant reviews of progress that has been made over the last several years and pointed to new areas of research and development needed by the business community in the United States. The session was well attended, with more than 100 persons present during the presentations.

J.H. Crawford, Jr.

University of North Carolina, Chapel Hill

Y. Chen

Oak Ridge National Laboratory

W.A. Sibley

Oklahoma State University

Chairmen
Principal Symposium Support

Department of Energy, Office of Basic

Energy Sciences

Defense Advanced Research Projects Agency

Army Research Office, Metallurgy and

Materials Science Division

Supplemental Support

Ceres Corporation

\section{MIRIS BULLETIN}

VOLUME VIII NUMBER 6

The Materials Research Society BULLETIN is published bi-monthly by the Materials Research Society for its members and others interested in materials science. Correspondence and submissioms are invited. They should be brief and typewritten (double-spaced). and the author's affiliation must be indicated. Address all material to the Editor.

\author{
President \\ H.J. LEAMY \\ Bell Laboratories \\ First Vice President \\ C.W. WHITE \\ Oak Ridge National Laboratory \\ Second Vice President \\ E.N. KAUFMANN \\ Lawrence Livermore Laboratory \\ Secretary \\ R.L. SCHWOEBEL \\ Sandia National Laboratory \\ Treasurer \\ K.C. TAYLOR \\ GM Research Laboratories
}

Executive Director

JOHN B. BALLANCE

Materials Research Society

9800 McKnight Road. Suite 327

Pittsburgh, PA 15237

(4I2) $367-3003$

Editor

T.G. MIDDLETON

P.O. Box K

Short Hills, NJ 07078 